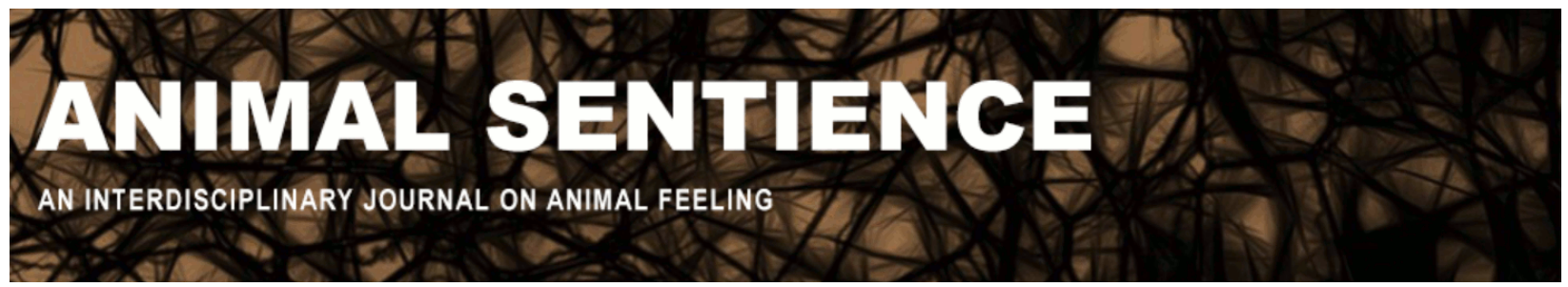

Chapouthier, Georges (2020) Invertebrate cognition, sentience and biology. Animal Sentience 29(26)

DOI: $10.51291 / 2377-7478.1615$

Date of submission: 2020-07-06

Date of acceptance: 2020-07-17

(c)

This article has appeared in the journal Animal

Sentience, a peer-reviewed journal on animal

cognition and feeling. It has been made open access,

free for all, by WellBeing International and deposited

in the WBI Studies Repository. For more information,

please contact

wbisr-info@wellbeingintl.org.

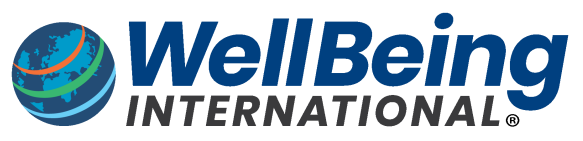

SOLUTIONS FOR PEOPLE, ANIMALS AND ENVIRONMENT 


\title{
Invertebrate cognition, sentience and biology
}

Commentary on Mikhalevich \& Powell on Invertebrate Minds

\author{
Georges Chapouthier \\ CNRS and Institut d'histoire et de philosophie de sciences et des techniques, Paris
}

\begin{abstract}
All animal species have adapted for survival and no species is superior overall. For cognitive capacities and sentience, invertebrates such as the octopus, although quite unlike vertebrates, can achieve similar performance levels. So can other invertebrates with small brains; hence they too, as sentient beings, deserve moral consideration from humans. How are we to identify these species? Only though a detailed analysis of their behavior. The decision, which is a moral judgment, depends on biological knowledge that still needs to be acquired.
\end{abstract}

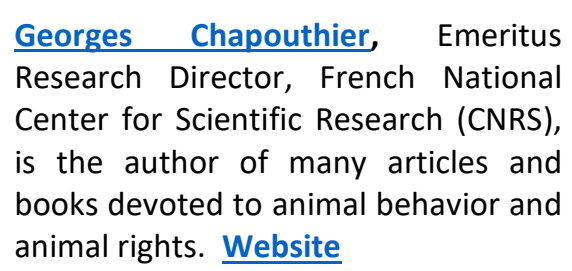
animal rights. Website

1. From Darwin to the Mind. A linear (and misguided) conception of the evolution of living species sees vertebrates (a group that includes the human species) as the peak of biological complexity as well as intelligence (Chapman \& Huffman, 2018). Vertebrates comprise a very homogenous group of species with highly developed brains; they have been shown to have outstanding cognitive skills, such as those of birds and mammals (Chapouthier, 2015). Most philosophers addressing practical moral issues in the relation between human and nonhuman animals restrict the scope of their analysis to vertebrates - sometimes just to the sub-group of mammals (Regan, 1983). Mikhalevich \& Powell (2020) (M\&P) note in their target article that many still have a binary view, distinguishing vertebrates from all other beings in the animal kingdom, classified as invertebrates, even though invertebrates are a heterogenous group ranging from highly intelligent animals, such as the octopus (Mather 2019), to animals with no nervous system at all, such as the sponge (Leys et al., 2019)

Darwin's theories have shown that the world of living beings is not a linear structure; it ramifies to form branches and divisions. All species have developed their own means of survival and reproduction. No single species can be ranked as superior or inferior to the rest. As M\&P note, cognitive skills emerge at irregular points in the evolutionary tree. Cephalopod molluscs, including the octopus, form a group that could be described as "modified snails." They have been found to achieve the same performance levels as vertebrates even though there is no direct anatomical relationship of descent between them. The same is true of social insects, likewise capable of extremely complex and intelligent behavior despite the small size of their brains. M\&P are making a well-founded and valid point when they state that "the nearly wholesale exclusion of invertebrates with central nervous systems from bioethics and science policy is not justified by the current state of the evidence." After reading their excellent target article and the many references cited, it is impossible not to reach the same conclusion. 
2. Moral Considerations and Biology. I would like to follow up a point made by M\&P that needs to be treated in greater depth: "the same kinds of data and reasoning that justify moral protections for vertebrates favor extending similar protections to some invertebrates" [my italics]. How can we find and agree upon a concrete specification of the way certain invertebrates should be treated? And which ones? How can M\&P's theoretical argument be developed and put into practice, first in moral terms, and then in legal terms?

As urged by Jeremy Bentham (1780/1970), the question that needs to be answered concerns how to determine which animals can suffer - or, more accurately, which animals have consciousness, or are conscious of suffering, i.e. which animals can be described as "sentient" according to M\&P's definition, along with the "affective glossing of conscious experience"? In the tree of Darwinian evolution, it becomes a matter of finding the groups where a form of sentience emerges. The challenge is made more difficult by the fact that, like most biological processes, sentience probably emerges in gradual stages and not through a sudden shift from absence to presence. What a fish feels is not the same as what a human being feels (Woodruff 2017; 2020): How can the even greater differences between what we and crustaceans or insects feel be studied so as to guide us in how they ought to be treated?

I think the answer must be based on detailed ethological analysis of the behavior patterns of different invertebrates. There is not yet enough analytical work in this field. It is clear that, as stated in the Cambridge Declaration on Consciousness (2012), "the absence of a neocortex does not appear to preclude an organism from experiencing affective states." Positive and negative affect is an integral feature of sentience for moral purposes. It is clear from ethological studies that a small brain does not rule out the potential for a form of sentience: The findings of Elwood, $(2013,2020)$ on decapod crustaceans and of Stach et al (2004) on social insects such as bees support this. A small brain, however, does not automatically mean complex behavior patterns, emotions or sentience either, as in the case of the earthworm or the oyster.

Only detailed analysis of the behavior of invertebrates -- species by species, or even sub-species by sub-species or population by population -- can lead to answers on the moral stance to be adopted in practice. Here, as is often the case, the moral implications and the resultant legal provisions to implement concrete welfare measures to protect the rights of certain groups of invertebrates (Chapouthier and Nouet, 1998; Chapouthier, 2014) can only be established on the basis of more thorough scientific knowledge in the field of ethology. Biology is therefore an indispensable discipline in the work required to improve the practical application of moral judgments (Chapouthier, 2019). Moral philosophers and legal scholars endeavoring to make progress with such considerations are dependent on biologists for advances that are yet to be made.

\section{References}

Bentham, J. (1780/1970). An introduction to the principles of morals and legislation, London, GB: The Athlone Press, 282-283

Cambridge Declaration on Consciousness (2012). http://fcmconference.org/img/CambridgeDeclarationOnConsciousness.pdf

Chapman, Colin A. and Huffman, Michael A. (2018) Why do we want to think humans are different? Animal Sentience 23(1) 
Chapouthier, G. (2014). Animal Rights, Encyclopedia of Global Bioethics (online) https://link.springer.com/referenceworkentry/10.1007/978-3-319-05544-2 221 Dordrecht, Germany: Springer Science+Business Media, Doi 10.1007/978-3319-05544-2_22-1 \#

Chapouthier, G. (2015). From animal intelligence to animal rights, in: Favre D. and GimenezCandela T. (editors), Tirant la Blanch, Spain: Animales y Derecho, 147-161

Chapouthier, G. (2019). Les droits de l'animal sous l'éclairage de la biologie, Revue philosophique, 3, 325-334

Chapouthier, G. \& Nouët J.-C., editors (1998). The universal declaration of animal rights, comments and intentions, Paris, France: Editions Ligue Française des Droits de l'Animal.

Elwood, Robert W. (2020) Do arthropods respond to noxious stimuli purely by reflex? Animal Sentience 29(10).

Elwood, R. W. (2013). Can we infer pain in crustaceans from behaviour experiments? in: Auffret Van der Kemp T., Lachance, M. (editors), Animal suffering - From science to law, Toronto, Canada: Carswell, 125-134.

Leys, S. P., Mah, J. L., McGill, P. R., Hamonic, L., De Leo, F. C., \& Kahn, A. S. (2019). Sponge Behavior and the Chemical Basis of Responses: A Post-Genomic View. Integrative and Comparative Biology, 59(4), 751-764.

Mather, Jennifer (2019) What is in an octopus's mind? Animal Sentience 26(1)

Mikhalevich, I., \& Powell, R. (2020). Minds without spines: Evolutionarily inclusive animal ethics. Animal Sentience 29(1).

Regan, T. (1983). The case for animal rights, California, USA: University of California Press.

Stach, S., Benard, J. \& Giurfa, M. (2004). Local-feature assembling in visual pattern recognition and generalization in honeybees, Nature, 429, 758-761.

Woodruff, M. L. (2017). Consciousness in teleosts: There is something it feels like to be a fish. Animal Sentience 13(1).

Woodruff, M. L. (2020) Whether invertebrates are sentient matters to bioethics and science policy. Animal Sentience 29(16). 